\title{
Confucius and Plato on Virtue and its Implementation in Education for International Understanding: A Comparative Study
}

\author{
Yan Gao* \\ Department of Curriculum and Instruction, University of Victoria, Victoria, Canada \\ *Corresponding author: yangao@uvic.ca
}

Received December 18, 2014; Revised December 30, 2014; Accepted January 06, 2015

\begin{abstract}
In recent years, the Education for International Understanding (EIU) program has become popular in East Asia. The EIU program promotes "international understanding" and aims to cultivate people possessing characters and abilities that prompt mutual cultural respect and reduce conflicts through a variety of educational means. In EIU curricula the concept of virtue cultivation is targeted as the ultimate goal. Some scholars have claimed that we need a value system that is commonly accepted by countries to solve global conflict. But can a value system be commonly accepted across nations and cultures? The present study uses this question to compare two influential philosophers: Confucius and Plato, by examining their representations of virtue. The author found that although there are similarities in these two thinkers philosophies, the differences among these two ideological systems are considerable. Therefore, the author concludes that it is dangerous to assume we have one value system that is universally applicable. Based on my analysis, the author also makes recommendations for current EIU curricula. The author thinks the current EIU program needs to pay special attention to two layered goals. First, the basic layer: to let students know "the fact of others." In addition to that, EIU program needs to pay attention on the deep-seated level: "the reason of the fact" to reach international understanding.
\end{abstract}

Keywords: Education for International Understanding (EIU), virtue, Confucius, Plato

Cite This Article: Yan Gao, "Confucius and Plato on Virtue and its Implementation in Education for International Understanding: A Comparative Study." American Journal of Educational Research, vol. 3, no. 1 (2015): 25-30. doi: 10.12691/education-3-1-6.

\section{Introduction}

The concept of Education for International Understanding (EIU) was proposed by the United Nations Educational Scientific and Cultural Organization (UNESCO) after World War II. In 1974, UNESCO launched its recommendations concerning education for international understanding, co-operation and peace as well as education relating to human rights and fundamental freedoms. It defined the international understanding, co-operation and peace "to be considered as an indivisible whole based on the principle of friendly relations between peoples and States having different social and political systems and on the respect for human rights and fundamental freedoms" [1]. In the text of this recommendation, the different connotations of these terms are sometimes gathered together in a concise expression, “international education” (Terms I. 1.b). In the year 2000, the Asia-Pacific Centre of Education for International Understanding (APCEIU) was established through an Agreement between the Government of the Republic of Korea and UNESCO. According to APCEIU's official website, the mission of the Centre is to collaborate with educators and institutions to promote EIU regionally and internationally since EIU "strengthens participatory democracy, protection of human rights, social and economic justice, inter-cultural respect, ecological sustainability, and nonviolent and just reconciliation of conflicts" [2].

As part of the Asia-Pacific area, EIU program also became popular in China, drawing attention from scholars, educators and policy makers in contemporary educational discourses. Some scholars claim that EIU focuses on "human rights, peace and democracy"; promotes international understanding, and cultivates people possessing characters and abilities that prompt mutual cultural respect so that global issues can be solved based on a common platform. In order to cultivate the role of the “global citizen,” scholars proactively design curricula with regional characteristics. The current EIU curriculum in China infuses the idea of "international understanding" into subjects taught in schools, that focus both on an understanding of Chinese history, culture, and national conditions as well as world issues such as peace and development, environment, and the coexistence of diverse cultures - to name but a few. In addition, as part of the curriculum, virtue cultivation is targeted as the ultimate achievement. Some scholars state that because international conflicts still exist, there is a need for a value system that is commonly accepted by countries to 
safeguard world peace and ensure the sustainable development of the planet. The same human value system is the key point to solve global issues [3].

However, does $a$ universal human value system exist? By focusing on this question, my purpose is to force myself and others, who hold the opinion that there is something in common we can achieve regardless of our different human nature, to reflect on this essential inquiry. If we do have one single value system, what are the characteristics of it? If we do not have such a system, how can we reach a basic understanding to avoid conflicts that do harm to peace and human populations? In order to help myself reflect and sort out those questions, and also to rethink the curriculum of EIU, I decided to trace ideas about human value systems back to their origins: inquiry about virtue arose more than two thousand years ago with thinkers such as Confucius - in the east - and Plato - in the west.

According to the Oxford Dictionary of Philosophy:

A virtue is a trait of character that is to be admired: one rendering its possessor better, either morally, or intellectually, or in the conduct of specific affairs. But different conceptions of moral virtue and its relation to other virtues characterize Platonic, Aristotelian, Stoic, Christian, Enlightenment, Romantic, and 20th century ethical writing. These divisions reflect central preoccupations of their time and needs of the cultures in which they gain predominance [4].

The concept of virtue has a great range of interpretations in different cultural and ideological systems. It is impossible to compare all of them in this study. Therefore, I will focus on two: Confucius and Plato. Confucius (551-479 BC) is regarded as the "First Teacher", or "Great Sage" in East Asian culture. His philosophical theory and value system has impacted the entirety of Chinese history and continues to have a formative influence on Chinese society today. Plato (424/423 BC- 348/347 BC) is the pioneer of western philosophy and helped to lay the foundations of western philosophy. Both of them play a foundational role in their philosophy respectively and both talked about virtue and how to teach virtue in ways that reflected their value systems. I do not intend to use their thoughts to generalize or even let them override other thinkers however, choosing these two philosophers' ideas allows me look closely and compare their thoughts that have great impact on modern society. Therefore, in the following, I will summarize their ideas about virtue and then examine the similarities and differences, and how their thinking might be implemented in EIU programs.

\section{Methodology}

This study uses document analysis as the research method. The author examined the original classical document Analects by Confucius and English translated version of Meno and Gorgias by Plato. The author also searched documents about "international understanding" by UNESCO, and browsed the Asia-Pacific Centre of Education for International Understanding (APCEIU) official website for EIU announcement, missions and latest news.
The present study uses comparative and contrast analysis. First summarizes the developing of virtue by Confucius, and the developing of virtue by Plato, and then based on the summary analyzes the similarities between those two systems, at last examines the differences about virtue on the two systems.

\section{Comparative Analysis}

Plato lived in a time when Greek society was at war, and his home of Athens came into a predicament. Athenian society's morals had become depraved, and Plato painstakingly sought a good way to save the country. In the late spring and autumn period when Confucius lived, the system of slavery collapsed, along with the contests between political forces, and frequent wars and riots that severely impacted and undermined the patriarchal system. In similar historical situations, Plato and Confucius spontaneously attached importance both to virtue and teaching virtue in order to restore a social system. In the following section, my analysis will be based on the texts Analects, Meno and Gorgias to find out Confucius' and Plato's respective thoughts about virtue.

\subsection{Developing Virtue: Confucius}

In Analects, Ren has the central role throughout the whole text, and Confucius endeavors to pass on the true sense of Ren to his students and spread the idea of Ren to society. Ren has been perceived and translated as "goodness," "humanity," "kindness” and "benevolence” in English. However, Ren in Analects developed beyond the particular. Chan [5] was the first to conceive Ren as general virtue. He stated, "Confucius was propagating a comprehensive ethical doctrine which must have a basic virtue on which all particular virtues are rooted” (p. 107). Confucius [6] emphasized Ren as the foundation and root of being a human. "One who is Ren sees as his first priority the hardship of self-cultivation, and only after thinks about results or rewards. This is we might call Ren" (Analects, 6.22). Thus, " the firm, the enduring, the simple and the modest are near to (but not) Ren” (Analects, 13.27) and "a clever tongue and fine appearance are rarely signs of Ren” (Analects, 1.3), since Ren pertains to inner cultivation. Ren is also the "goal and product of ritual action and significating, the embodiment of the cultural tradition as authoritative person" [7]. Confucius [6] said, "A man who is not Ren - what has he to do with ritual action?” (Analects, 3.3). Confucius places Ren as the ultimate objective, he sighed: "Having in the morning heard the way (of being Ren), one could die that evening without regret” (Analects, 4.8). Confucius regarded Ren as one's conscience, the principle and foundation of being a human, the only way to achieve full humanity (Analects, 6.17). Ren as the basic virtue in Chinese history and society can include the characters such as "goodness," "humanity," "kindness" and "benevolence", but it is not confined within these characters. Those are the external forms of Ren, the internal form links with "self." Ren is a process of self-cultivation. During the process of achieving the ultimate objective of Ren, one needs selfdiscipline, self-fulfillment and self-perfection.

In Analects, other than the essential concept of Ren, Confucius [6] also stated his views on how to achieve Ren 
and features of Ren, claiming the abstract concept is not far beyond one's reach. "Is Ren really so far away? If I simply desire it, I will find the way to reach it" (Analects, 7.30). By "restraining yourself and returning to the rites constitutes Ren. If for one day you managed to restrain yourself and return to the rites, in this way you could lead the entire world back to Ren. The key to achieving Ren lies within yourself - how could it come from others?” (Analects, 12.1) The way Confucius suggested to achieve Ren corresponds with how he defined Ren - a selfcultivated, self-disciplined, self-fulfilled process, and one needs to confine the inner part of oneself so that it can be converted to the external presentation and behavior. Ren has several external manifestations. Confucius considered "respect," "care" “courage" and "uprightness" as components of Ren. Thus, a virtuous man should first be a good son, and when he steps out into society, he needs to be sensitive to others' feelings in order to transform respect into commitment for his official responsibility. Finally Ren requires love for fellow human beings [8]. Other than this, the external manifestations of Ren need to be guided by ritual. Insufficient or excessive action is not considered Ren. "Do not look, do not listen, do not speak and do not move unless it is in accordance with ritual” (Analects, 12.1). Ritual is the norm of Ren. Overall, in Confucius' ideological system, Ren is the inner cultivation of roots in a human's heart, "no scholar-official of noble intention or virtuous person would ever pursue life at the expense of Ren, and in fact some may be called upon to give up their lives in order to fulfill Ren” (Analects, 15.9). For Confucius, Ren is something that is worth pursuing even at the cost of life [6].

\subsection{Developing Virtue: Plato}

Plato [9] focused on the discussion of virtue in Meno. Meno came to Socrates - Plato's teacher and mentor - and asked whether virtue is teachable or not teachable. This question triggered the discussion of virtue between Socrates, Meno and Anytus. Meno defined virtue as “ a man is to be capable of managing the affairs of his community, and of doing so in a way that enables him to help his friends, harm his enemies, and avoid suffering any harm himself" and a woman "should be a good housekeeper, which is to say that she should keep the indoor property safe and obey her husband" (Meno, 71e). However, Socrates disagreed with Meno about dividing virtue according to one's gender and position. He thought, "even if there are many aspects of virtue, of different kinds, they all share a single characteristic” (Meno, 72d). Although in Meno, Socrates did not provide a precise definition, but rather stated that virtue has certain qualities. He tacitly approved of what Meno thought: "courage is a virtue, as are self-control, wisdom, and nobility - but there are a great many others too" (Meno, 74a). Among them, he emphasized justice and self-control. He thought people could be considered good people only if they are selfcontrolled and just (Meno, 73b). As one quality of virtue, justice also appeared in discussion in Gorgias [10]. Socrates treated justice as a "moral physician" that cures men of their excesses and makes them better people” (Gorgias, 478). During this conversation, Meno made another statement that virtue is wanting good things and having the ability to get them” (Meno, 78a). According to him, virtue is the ability to procure good things (such as health and wealth) for oneself. Socrates did not disagree with Meno but continued that, "even though it procures good things, this procurement must be attended by justice or self-control or morality, or some other aspect of virtue, if it is to be virtue" and "any behavior that is attended by justice is virtue” (Meno, 78e). Meno then provided another definition of virtue that virtue is any action that is accompanied by a part of virtue. However, Socrates thought only if Meno gives the precise definition of virtue can this statement be proved to be true. Seen from the above discussion, Socrates did not define what virtue is, but thought justice and self-control are qualities of virtue, and the prerequisite of seeking or achieving virtue [9].

In the text of Meno [9], the topic then shifted from "what is virtue" to "whether virtue is teachable." If virtue is a kind of knowledge then it is teachable. "Knowledge is true beliefs inside him, which are awoken by questioning and become pieces of knowledge, his soul will have been in a state of knowledge for all time” (Meno, 86a). Thus, according to this conversation, Socrates at this stage thought virtue is a kind of true belief inside humans and embedded with soul. The externalized manifestation of this true belief is knowledge. When mental endeavor and persistence are guided by knowledge, they end in happiness but if they are guided by ignorance, the opposite occurs (Meno, 88c). "When knowledge guides the soul, mental qualities become beneficial, and when ignorance guides them, they become harmful” (Meno, 88e). If we follow this logic, the benefits of knowledge as Socrates described them can also be applied to virtue since the presupposition of this conversation is: virtue is a form of knowledge. Therefore, virtue is good - good makes us do good. When Anytus joined the discussion with Socrates and Meno about who is the teacher of virtue, he held the opinion that one generation "learnt from the previous generation of decent gentlemen” (Meno, 93a). During the conversation concerning how Themistocles and Pericles educated their sons, we can infer that Plato thought virtue should be transmitted from generation to generation. He thought virtue is not only worthy to pursue, but also needs to be inherited. In terms of the function of virtue, when argued with Callicles about oratory, Socrates said that, "a good orator will have speech or action by which he seeks to influence the souls of men, bring righteousness and moderation and every other virtue to birth in the souls of his fellow-citizens" [10] (Gorgias, 505). The purpose of virtue is not merely the focus on "self." All aspects of virtue should be "transmitted" to fellow-citizens, so virtue is a self-cultivation and a universal salvation $[9,10]$.

\section{Similarities}

After reviewing the main arguments about virtue, I found some similarities between Confucius and Plato. First of all, both of them confirm the importance and essence of virtue by placing it in a central position of textual discussion. Ren is the conception that focuses the entire Analects. Confucius [6] discussed what is Ren, why we need it and how to achieve it. On the basis of Ren, he promoted wisdom, courage, loyalty, faith, and righteousness as the externalized manifestations of Ren. He said: "If you set your heart sincerely upon Ren and you 
will be free of bad intentions” (Analects 4.4). In the same time in ancient Greece, Meno asked Socrates what virtue is and whether it is teachable or not. The fact that Meno occupies an entire chapter in Plato's writings indicates that virtue is the main concern of Plato. He concentrated on trying to logically summarize its characteristics not only in Meno but also through his other writings. In Plato's view, virtue is the highest realm, "justice," "bravery" "wisdom," and "moderation" are the practical principles of virtue.

Secondly, both of them furnish a unified definition of virtue, but also state how a virtuous person should behave. For instance, Confucius [6] stated that a virtuous person should love and care for others (Analects, 12.22); "have filial piety and respect for elders” (Analects, 1.2); be well behaved and respectful; serious and conscientious (Analects, 13.19); and also clement, honest, diligent, kindhearted (Analects, 17.6). Plato [9] emphasized justice and self-control as the qualities of virtue, and did not deny what Meno said: "courage is a virtue, as are self-control, wisdom, and nobility-but there are a great many others too" (Meno, 74a). They agreed that self-control and selfdiscipline are ways to achieve the state of virtue.

Thirdly, in terms of teaching, both of them thought education should be differentiated. The method of education should be in accordance with students' capability and meet their needs. Confucius [6] devoted to teaching students in accordance with their aptitude. He said: "you can discuss the loftiest matters with those who are above average, but not with those who are below average" (Analects, 6.21). He answered differently to the same question asked by different students, and he believed each student has their own approach to study. Plato [9] also held the same ideas around education. He described a situation in Meno when Socrates guided a slave to solve a Geometry problem, Socrates said: “If you don't want to use numbers, at least point to the line that would produce it” (Meno, 84a). Both of them allow students to approach knowledge in their way and teach them according to their aptitude.

Fourthly, if we examine the texts closely, we can find that they considered aesthetics as one aspect of virtue. Specifically, Confucius [6] links Ren with aesthetics: "to live in the neighborhood of Ren is a beautiful thing" (Analects, 4.1). He also said that, "A man who is not Ren - what has he to do with music" (Analects, 3.3). In Analects, Confucius highlighted the function of aesthetics in the process of self-cultivation. According to his philosophy of education, true aristocrats should possess six arts: ritual, music, archery, horsemanship, calligraphy (painting) and mathematics. He stated that one should lean upon Ren, and "explore widely in one's cultivation of the six arts” (Analces, 7.6). Plato [10] also includes aesthetical aspects in his statement that, "the excellence of a thing depends on its having a certain ordered beauty which is the result of arrangement" (Gorgias, 507). Coincidentally, when referring to the artistry that one virtuous man should possess, Plato also mentioned similar skills. When talking about inherited virtue, he mentioned Pericles who was a virtuous man and taught his sons skills, "such as music and sports" (Meno, 94b). Another virtuous man, Themistocles, "had his son taught to be a good horseman, at least, in the sense that he could keep an upright seat on horses” (Meno, 93d). Overall, Confucius and Plato affirmed the importance of virtue. They discussed virtue as processes of self-control and selfcultivatation for human beings, and the education of it they deemed essential to maintain a reasonable level of social order.

\section{Differences}

Due to the different historical conditions and cultural background, Confucius and Plato's thoughts about virtue also differ in various ways. First, they have different ideological foundations. As stated above, with Ren as the core concept, Confucius promotes love, filial piety, and emphasizes restraining oneself to return to ritual. His ideological system tends to focus on family, clan and societal norms. He elucidated his thoughts on virtue, moral education, and management through the traditional concept of patriarchal kinship, based on the interpersonal relations and real problems of man and society. His emphasis is on maintaining a patriarchal system and hierarchy. However, Plato's ideological system based on ancient Greek society and law mainly addresses citizens' relations. With "justice" in this category, Plato discussed the functions of the state, and the rights of individuals. Thus, as a citizen, one was responsible for the welfare of the city, therefore, for Plato, virtues are essentially public [8] (p. 80). Starting from the benefits of slave-owning aristocracy, he taught students to pursue the ultimate goal of "perfection." In terms of virtue, he held the opinion that the virtue of good people "comes to them as a dispensation awarded by the gods, without any knowledge" (Meno, 99e).

Second, although both Confucius and Plato think the pursuit of virtue needs external norms and principles to regulate, they refer to different means of regulation. In Confucius' ideological system, ritual is the Ren-based norm that regulates people. He insisted that one needs to restrain oneself and return to rites to achieve virtue [6] (Analects, 12.1). Plato's system treats justice as the physician to make people become better [10] (Gorgias, 478). Justice is the individual's own internal moral conflicts, adjustment and harmony. For society it is the social division of labor after coordination. He claimed that justice must attend any procurement for good and "any behavior that is attended by justice is virtue" [9] (Meno, 78e).

Third, Confucius and Plato held different opinions about the approach to virtue. Confucius stressed the unity of knowledge and emphasized devotion to practice Ren. He used vivid metaphors to teach students, encouraging students to practice drawing moral inferences about other cases from one instance. Plato emphasized the role of knowledge in the process of education and social impact. He stressed logical reasoning and taught students to use rational moral judgments to guide behavior. If Plato is more concerned with the pursuit of moral knowledge, then Confucius places more emphasis on the cultivation of morality and the enlightenment of moral obligations [11]. In the case of Plato [9], teaching is a process of recollection. "The process of learning is in fact nothing but recollection. There's no such thing as teaching” (Meno, 81d \& 81e). In Confucius’ [6] system, he said:

I will not open the door for a mind that is not already striving to understand, nor will I provide words to a 
tongue that is not already struggling to speak. If I hold up one corner of a problem, and the student cannot come back to me with the other three, I will not attempt to instruct him again” (Analects, 7.8).

It seems Confucius also thought there are conditions for teaching and instructing, but he did not deny the function of teaching, he thought knowledge needs to be transmitted or taught by teachers to students.

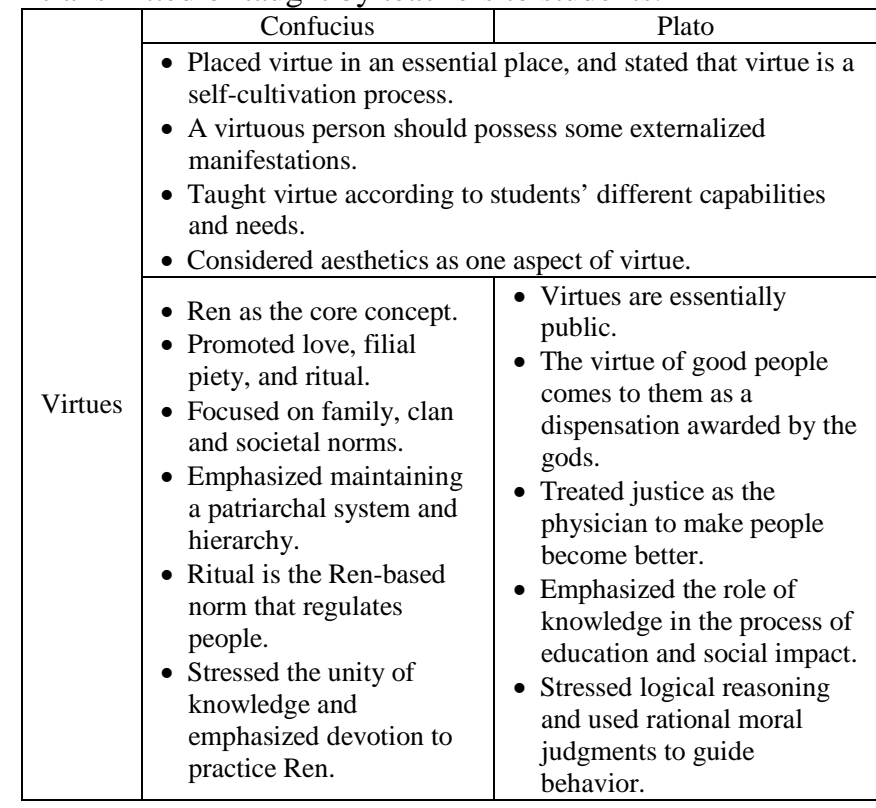

\section{Conclusion}

From the analysis above, we can conclude that two influential thinkers of the ancient world who had no contact with one another, placed virtue in an essential place, and stated that virtue is a self-cultivation process. A virtuous person should therefore possess some externalized manifestations such as courage, honesty, love, and self-control. In addition to that, both Confucius and Plato applied the idea that teaching should be according to students' different capabilities and needs. They also considered aesthetics as one aspect of virtue. However, since they lived under different geographical and historical conditions, their ideological systems are also distinct from each other. Confucius focused on Chinese traditional patriarchal kinship, elucidating his thoughts on virtue based on family, clan and societal norms, using the underlying mandate of maintaining a stable system of patriarchy and hierarchy. Plato emphasized justice, individual rights, and using law to adjust citizens' relations and build social order. Although both of them thought virtue is externally regulated, Confucius thought in order to engage with Ren, we must return to ritual, while Plato thought justice is the key to regulating behavior. With regard to the way to pursue virtue through education, Confucius thought virtue can be taught and students need to practice it in daily life. Plato, by contrast, stressed the process to achieve knowledge, describing teaching as a recollection process and emphasizing logic and reasoning in this process.

\section{Discussion}

After analyzing the similarities and differences between Confucius and Plato, we need to return to the current education program we have discussed-Education for International Understanding. I agree and advocate that under the current situation of globalization, such a program is significant and meaningful. Globalization offers undeniable benefits, but also presents new challenges and causes problems. It introduces many profound changes that "require new theories and language system” [12] (p. 46). Our world is shrinking as technology erodes the constraints of distance and time. With accelerated interdependence, the volume of communication has changed. Therefore, “for today's professionals, students and other educated citizens, a knowledgeable, critical, evaluative, and action-oriented gaze is a practical necessity”. As human service professionals, we must "know where to look, what to look for, and what to do" [12] (p 54).

Obviously, the EIU program has value. However, we all want to guarantee that it will not become a mere formality. As far as I am concerned, based on my analysis of Confucius and Plato, the current EIU program needs to pay special attention to two layered goals. First, the basic layer: EIU program needs to let students know "the fact of others." The facts are these: we have more than two hundred countries in our world, and most of them speak different languages and have their own cultures. They have different value systems, and therefore we may have different views toward the same concept, such as virtue. I interpret this as the "knowledge layer." The current EIU curriculum used in China focuses on this layer and does a good job educating students on cultivating an international viewpoint. However, it is not enough to only focus on this level. In order to achieve real understanding, and avoid conflicts to the greatest extent, the advocates and practitioners of the EIU program need to pay attention on the deep-seated level: "the reason of the fact". What I mean here is: educating students beyond the knowledge level to conceptualize the reason for the knowledge so that when they encounter conflicts, or when they communicate with people from other countries and regions, they will be aware of different behaviors and even understand the reason and motivation behind those behaviors. For example: after examining the different perspectives toward virtue from Confucius and Plato, we understand that Confucius was concerned about maintaining a patriarchal system and hierarchy while Plato was concerned with issues of justice and early democracy. Therefore, it is not difficult to explain why countries under the influence of Confucianism, such as China, Korea, and Japan still hold great value on hierarchy in both the work place and daily life, whereas western countries such as the United States and Canada advocate social justice and democratic processes. Thus, the current curriculum of EIU needs to not only embed factual knowledge but also needs to present the roots and reasoning behind that knowledge for students. We should also be aware that democracy encourages contributions from different voices. Seeking similarities between value systems does not mean putting down the difference of others. We don't expect students to immediately understand other cultures, but at least we can offer them a scaffold with which to achieve a better understanding. 
While comparing the two influential value systems of Confucius and Plato, the author found both similarities and differences. The author acknowledges that these two thinkers cannot represent the whole eastern and western ideological system; however, by examining these two, the author can conclude it is dangerous to assume there is a commonly accepted value system upon which EIU can be grounded. Therefore, my critical point is this: the implementation of EIU and any other educational program devoted to globalization and international citizenship should not only focus on learning language and factual knowledge but also address cultural and philosophical differences.

\section{Acknowledgement}

For encouragement, support, and frank criticism at various stages of the development of the present paper, I am deeply indebted to Professor Graham McDonough and Professor Helen Raptis, who constantly guided and helped me through the process of my writing, without whose illuminating suggestions and careful revisions, the present paper should not have been attempted.

\section{References}

[1] United Nations Educational, Scientific and Cultural Organization, Recommendation concerning education for international understanding, co-operation and peace and education relating to human rights and fundamental freedoms. Available:
http://www.unesco.org/education/nfsunesco/pdf/Peace e.pdf [Accessed Apr. 2, 2014].

[2] Mission of The Asia-Pacific Centre of Education for International Understanding. Available: http://www.unescoapceiu.org/ [Accessed Apr. 2, 2014].

[3] Yang, X., "Research on the theory and practice of Education for International Understanding” (Master thesis), Apr. 2006. Available: http://www.cnki.net/.

[4] Blackburn, S., The Oxford Dictionary of Philosophy, Oxford University Press, New York, 2008.

[5] Chan. W.T., "Chinese and Western interpretations of Jen (humanity).” Journal of Chinese Philosophy, 2, 107-129. Mar.1975.

[6] Yao, J., Lun yu shuo jie [Lexical analysis of Analects], Qi Lu Shu She, Jinan, 2003.

[7] Hall, D. L., and Ames, R. T, Thinking through Confucius. State University of New York Press, Albany, 1987.

[8] Yan, A. Z., An existential reading of the Confucian Analects, Cambria Press, New York, 2011.

[9] Sesonake, A., and Fleming, N. (Eds.), Plato's meno: text and criticism, Wadsworth Publishing Company, Belmont, 1965.

[10] Plato., Gorgias. (W. Hamilton, Trans.), Penguin Books, Baltimore, 1960.

[11] Yu, Z., "Comparison of Moral Education Thought of Confucius and Plato". In Chinese local Chronicles on Research of education, (Eds.), Memorial of < History of Education > 20th Anniversary Proceedings (16) - the history of foreign educational thought and character study, China Academic Journals, Beijing, 2009.

[12] Roth, W., and Briar-Lawson, K. (Eds.), Globalization, social justice, and the helping professions. State University of New York Press, Albany, 2011.

[13] Du, D., Lun yu xin zhu xin yi: fu zhu yao zi ci, ren ming suo yin [New note and translation of Analects, main names and words index attached], Zhong hua shu ju, Beijing, 2011.

[14] Ivanhoe, P. J., and Norden, B. W. V. (Eds.), Readings in classical Chinese philosophy (2th ed.). Hackett Publishing Company, Indianapolis, 2001.

[15] Teloh, H., The development of Plato's metaphysics. Pennsylvania State University Press, University Park and London, 1981. 